\title{
Gnosticismo, política y religión Aproximación crítica a una relación fundamental en Eric Voegelin
}

\author{
Diego Fonti* \\ Universidad Católica de Córdoba, Córdoba, Argentina
}

\section{RESUMEN}

Eric Voegelin afirma que hay un vínculo entre un modelo de religión y un modo de realización de lo político, caracterizado por la masificación, la falta de conciencia de los individuos, y la figura 'iluminada' del líder. Esta interpretación se ve enriquecida y complejizada a partir de su interpretación del gnosticismo, como clave de lectura para comprender a los más influyentes filósofos y movimientos políticos desde la Ilustración. El presente trabajo busca reconstruir filosóficamente, en primer lugar, la relación que se dio entre el campo teológico-político y el gnosticismo, para luego abordar las posibilidades y límites del pensamiento de Voegelin. Se analiza así su comprensión del gnosticismo y la estructura común que identifica en religión, filosofía y política contemporánea. Se propone finalmente una crítica, en la que se aduce el valor que lo teológico político asume desde la perspectiva latinoamericana. Esta crítica pretende al mismo tiempo abrir las posibilidades positivas y constructivas que lo teológico-político y la experiencia religiosa pueden abrir en América Latina.

Palabras clave

Política, religión, gnosticismo, teología política, América Latina

* Licenciado en Filosofía, Universidad Nacional de Córdoba, Argentina, y doctor en Filosofía, AlbertLudwigs Universität, Friburgo, Alemania. Investigador Conicet y de la Universidad Católica de Córdoba, Argentina. Docente titular de Ética y vicerrector académico, Universidad Católica de Córdoba, Argentina. Correo electrónico: diegofonti@gmail.com. 
Gnosticism, politics and religion. A critical approach to a fundamental relationship in Eric Voegelin

\section{ABSTRACT}

Eric Voegelin states that there is a connection between a model of religion and a way of doing politics, characterized by mass movements, the lack of conscience of the individuals and the 'illuminated' figure of the leader. This interpretation is enriched and made more complex by means of his interpretation of Gnosticism, as keynote to understand the most influential philosophers and political movements since the Enlightenment. This essay aims, first, to philosophically reconstruct the relationship between Political Theology and Gnosticism, and second, to understand the possibilities and limits of Voegelin's theory. His understanding of Gnosticism is researched, as well as the shared structure that he identifies in contemporary religion, philosophy and politics. Finally this Essay undertakes a critique, where the value that the theological-political field assumes in Latin America is brought up in argument. At the same time, this critique attempts to open the positive and constructive possibilities that political theology and religious experience can open up in Latin America.

\section{Keywords}

Politics, religion, Gnosticism, political theology, Latin America

Una premisa que atraviesa este trabajo es la necesidad de ubicar las cuestiones vinculadas con la experiencia religiosa no en el campo de la 'filosofía primera' o metafísica, sino en el ámbito de la filosofía práctica. Esto puede parecer una afirmación sin mayores compromisos, pero de hecho implica que el modo filosófico de lidiar con las experiencias relacionadas con lo religioso no han de atender tanto al problema de los sentidos de verdad o realidad de las entidades en juego y nuestras afirmaciones sobre ellas, sino que de modo primario -y más constitutivo- al modo en que dichas experiencias, afirmaciones y entidades configuran una serie de prácticas y sentidos en las personas y los grupos. Así, habría que agregar la filosofía de la religión al elenco aristotélico de la filosofía práctica, que tiene que ver con las cosas relacionadas con la acción y libertad humanas, o sea, las cosas que no están sometidas a un orden 'natural' e inmutable sino que pueden ser de otro modo, como lo son la ética, la política, y la economía. Precisamente, un aporte en este esclarecimiento de relaciones puede venir de una filosofía de la religión que 
intente estudiar cómo se vincula la construcción teórica de lo religioso, la teología y la praxis política.

En clave filosófica, el sentido más antiguo e influyente del término gnosis proviene de Platón e indica un acceso cognitivo a lo verdaderamente existente, acceso que es condición necesaria de toda acción correcta (Cratilo 440). Para el helenismo, el concepto es siempre religioso, y transforma el sentido que se encuentra en los textos sapienciales y neotestamentarios, caracterizados por la idea de conocimiento de la vida y de Dios, pero también de prudencia en la acción, y comienza a relacionarse con un tipo de verdad de salvación.

Una segunda vertiente platónica del helenismo es el texto Las Leyes 896e, en el que se plantea, al inicio del orden cósmico, dos almas: una que es autora del bien y otra del mal. Por eso, para aquellos que fueron denominados 'gnósticos', se trataba de un acceso directo a la verdad, que es un conocimiento de esta estructura originaria y dual del mundo y de Dios, por un lado, y por otro, de un modo de redención por dicho conocimiento (Ireneo de Lyon, 2003, pp. 273-74). Dicho acceso tenía también como consecuencia que el mysterion debía permanecer así: secreto, no enunciable. Más allá de las diferencias entre las variantes gnósticas, es transversal a ellas que ese saber concede una naturaleza divina, y con ella, redención e inmortalidad. Todo lo intramundano, inclusive la mediación divina encarnada, debe ser superado por lo espiritual, luminoso e inmaterial. Por ello también se supera la creencia por el conocimiento, así como el Dios del Antiguo Testamento por el del Nuevo. Y lo esencial a este tipo de pensamiento es una estructura metafísica que liga, por un lado, espiritualidad, bien y conocimiento, y por el otro, la ignorancia, la materialidad y el mal. Es importante notar que esta duplicidad se ha expandido a partir de una comprensión determinada e influyente del cristianismo, pero que sin embargo le antecede y le sucede luego de la secularización. Aunque el helenismo tiene fuerte eco en la comunidad hebrea, su relación teológico-política dice más relación con la doctrina metafísica del origen del orden y las relaciones que impone a los individuos respecto del todo que con las tradiciones de los profetas y las críticas divinas a los sistemas instituidos, en especial aquellas que violentan las dignidades personales y comunitarias.

Aunque este artículo elaborará detenidamente el pensamiento de uno de los siguientes filósofos, conviene anticipar que con Topitsch y Voegelin el concepto de gnosticismo abandona contemporáneamente su lugar religioso-teológico y avanza en una dirección de crítica de las ideologías, retomando cada uno a su modo la impronta spinozista. A pesar de que en la actualidad el interés por el gnosticismo no es directamente teológico, son justamente las obras -que estudian tanto la raíz teológica como el sistema de pensamiento que la fundamenta-, las que permiten una 
comprensión más clara y una traslación de los conceptos y cosmovisión gnósticos a otros campos, como por ejemplo, el texto fundamental de Hans Jonas (2001). La obra de este muestra tanto la injerencia helénica como la apropiación cristiana de la misma, en doctrinas como la de los dos dioses, la restauración del pleroma y la tarea humana, y los diversos dualismos gnósticos. Tanto la comprensión dualista y maniquea del mundo como la creencia en la posesión de un conocimiento iniciático y de una tarea mesiánica por vía de negación del mal encarnado en lo opuesto, son algunas de las características que Voegelin y Topitsch subrayan en los movimientos que actualmente adoptan la estructura gnóstica. Ambos consideran que hay analogías o afinidades electivas entre la comprensión gnóstica del mundo y algunos planteos políticos y filosóficos contemporáneos. En términos generales, mientras que Voegelin posee aún una estructura metafísica clásica, todavía ligada a una comprensión cristiana del mundo, Topitsch piensa el problema desde una teoría de las ciencias neopositivistas. El gnosticismo sería un pensamiento prepositivista y precientífico, atravesado por estereotipos que ligan las manifestaciones visibles con los mitos y los valores. Y su fuerza radica en la persistente idea de caída y necesidad de salvación, que aparece una y otra vez en sistemas filosóficos y en propuestas políticas que se piensan a sí mismas como iluminadas y como inductoras para miembros de la sociedad, portadores de una elección (Topitsch, 1988, pp. 26, 103-104, 296). Es quizá por sus compromisos cristianos que Voegelin propone una idea no positivista, sino más bien metafísica clásica de realidad, que intenta limitar los neognosticismos y su típica visión inmanentista del mundo, que incluye líneas tan variadas como el hegelianismo, el marxismo y el positivismo, pero también a Nietzsche y a Heidegger.

Una breve ubicación de Voegelin en la historia de las ideas puede resultar de ayuda para comprender los motivos principales de su pensamiento. Voegelin nace con el nuevo siglo (1901), crece en Alemania y Austria en época de guerra bajo fuertes injerencias políticas de las principales ideologías de su época. No es casual que por ello la Modernidad sea para Voegelin sinónimo de 'ideología', sintetizada en un sistema intelectual de ideas, que se cierra sobre sí mismo, sin prestar atención a la realidad, y cuyo objetivo fundamental es la inmanencia de la felicidad -reducida a prosperidad- terrena (McAllister, 1995, p. 17). De este modo se inicia una línea de pensamiento en Voegelin en la que toda afirmación positiva sobre la Modernidad -su proyecto emancipatorio, la limitación de los poderes carismáticos, la ruptura con la exigencia de adoptar un sistema de creencias unívoco, etc.- es sujeta a crítica de fundamentalismo, debido a su autofundación y a la eliminación de toda fundamentación trascendente. A inicios de la década de 1920 permanece dos años en Estados Unidos, lo que él llama 'la gran ruptura' 
en su pensamiento (Voegelin, 1989, p. 28). Desde allí interpreta lo que sucede en Europa uniéndolo a su lectura de Weber, con atención sobre todo a la 'ceguera' causada por la ideología. Su vuelta a Austria y su trabajo universitario, así como su producción literaria centrada en la crítica al uso político de la idea de raza y en la crítica a las 'religiones políticas', le significaron el rechazo del régimen nazi, hasta su cuasi forzosa emigración a Estados Unidos. En este país avanza con su estudio de cómo las sociedades producen una expresión simbólica de la realidad que da significado a su existencia, viendo en el orden cristiano y la separación agustiniana de dos ciudades, el proceso más cabal de un simbolismo operativamente logrado. Sin embargo, la Modernidad, según Voegelin, elimina la separación por vía de redivinización del mundo, que reemplaza la fe por la ideología. En esta idea de Modernidad como crisis, Voegelin, junto a otros como Leo Strauss y Hannah Arendt, influirá poderosamente sobre pensadores y políticos característicamente liberal-conservadores, que limitan las potencialidades emancipatorias de la Modernidad a una serie de derechos políticos liberales, pero que rechazan como ideologías las posiciones que pretenden subvertir órdenes económicos y políticos caracterizados como opresivos de las grandes mayorías.

Voegelin propone leer filosóficamente los fenómenos relacionados con el campo religioso-político. Pero antes de esbozar los rasgos principales de esta lectura filosófica, conviene aclarar el uso premeditado del término 'religioso-político'. En sentido estricto, Voegelin usa el término 'religión política' para entender los modelos políticos que conllevan una estructura religiosa caracterizada por el gnosticismo, que se expondrá a continuación. Pero su preocupación no es ajena a la 'teología política', en tanto la teología es la exposición racional de lo creído religiosamente, ni permanece incólume tal teología luego de la exposición voegeliniana. A partir de estas ideas introductorias vale indagar, en primer lugar, en cuál es el vínculo entre gnosticismo y teología política, buscando las relaciones filosóficas estructurales expuestas por algunos textos centrales de esta teología. A continuación, el artítulo se concentrará en Voegelin mismo y su comprensión del problema religioso político, para luego estudiar cómo el gnosticismo es utilizado por este pensador como clave de lectura y crítica de movimientos filosóficos, teológicos y políticos de su época. A partir de esta crítica, el paso subsiguiente es indagar en la reconstrucción de la 'ciencia política' propuesta por Voegelin. Todo esto no tiene un interés solo académico, sino que pretende también alcanzar algunas conclusiones de análisis práctico para situaciones contemporáneas, cual es el objetivo final de este trabajo, en el que se estudiarán los alcances y límites de la propuesta voegeliana, particularmente desde la situación latinoamericana. 


\section{El problema gnóstico y la teología política}

Se pueden proponer diversos accesos al estudio de la relación entre política y experiencia religiosa. De hecho, desde la Modernidad se hallan, a menudo mezcladas entre sí, posiciones que van desde la negación de lo religioso en su vínculo con lo político -desde el intento de supresión hasta la tolerancia-, pasando por modos de reconversión de lo religioso en instrumento estatal como religión civil, hasta llegar a los integrismos y, en medida insignificante en Occidente, al fundamentalismo. Pero estos modos históricos, que tienen un gran interés sociológico, son menos útiles a la hora de pensar la relación desde una filosofía de la religión. Para este aporte conviene, sin negar los datos históricos o sociológicos, moverse en el campo de sentidos y conceptos vinculados con esas experiencias. Por eso aparece útil la teología política como una determinación más específica y analítica de esta relación. Al mismo tiempo, siendo el gnosticismo un tema de fuerte presencia en el campo filosófico y teológico, se ven más claramente las posibilidades de iniciar este estudio desde la teología política.

La teología es el modo en que se expresa, de un modo comprensible y argumentativo, una serie de creencias no justificables desde otro campo científico de explicación. Como tal, la teología requiere de un tipo de adhesión previa a su propia elaboración. De otro modo, el estudio que la misma involucra podría situarse bajo diversos marcos epistemológicos (como la historia de las religiones, la hermenéutica de textos antiguos, etc.), pero no entraría en el espacio denominado teología. Esta primera afirmación debe tenerse en cuenta a la hora de estudiar el punto de partida de la teología política en el siglo XX, Carl Schmitt.

Si bien Schmitt es un confeso creyente, su uso de la teología está dado desde el derecho y desde una justificación de la utilidad de la configuración legal y política del catolicismo romano como base de toda la configuración legal y estatal occidental. Así, su 'teología política' debe matizarse en tanto teología, y acentuarse su injerencia como filosofía política o filosofía de la religión. Por ello, estudios relevantes actuales muestran a Schmitt menos influido por convicciones cristianas, entre ellas la siempre tensa relación con la apocalíptica heredada del judaísmo y parte inherente de toda teología que como representante de una "gnosis truncada" (Manemann, 2002, p. 168). Aquí se halla un acceso muy valioso al problema de la relación entre teología política y gnosis, porque aunque a menudo se haya pensado que siempre la inspiración política monoteísta tendría que ver con el problema del mesianismo y un aceleramiento del tiempo y su fin, de hecho lo que sucede en Schmitt es que la demora del fin impulsa su elaboración de la katech óntica, o el modo de permanencia y fidelidad a una comprensión trascendente del mundo y 
de la autoridad ante el avance de comprensiones distintas e inmanentes. La hostilidad del gnóstico ante el mundo no toma aquí la vía de un escape espiritualista, sino del ejercicio de soberanía que intenta imponer al mundo una comprensión determinada.

Al final de su Teología politica II (Schmitt, 2009, p. 130), Schmitt vuelve sobre el problema del gnosticismo y la supuesta tensión entre el Dios creador del mundo y el Dios que debe redimir ese mismo mundo malogrado. Este autor no busca responder a ese problema, sino que su objeto es responder a Blumemberg, respecto a que el ser humano autocreador y autorredentor de la Modernidad, fuente única y última de legitimación, no es sino una imagen secularizada de la antigua estructura religiosa. Blumemberg (2008) considera sustancialista a toda interpretación que niegue autonomía a la modernidad mediante nociones que corresponden a una filosofía teológica de la historia, que tome aspectos como providencia o escatología, y mediante la operación de remoción del aspecto religioso mantengan idéntica estructura trascendente. De este modo es para Blumemberg indeseable hablar de secularización, en tanto ese concepto quita el potente principio de autolegitimación esencial para la modernidad. Lo que Blumemberg no hace es tener en cuenta el contexto de producción y los compromisos existenciales que portan en su sistema de creencias aquellas personas que toma en su texto como modelos para la autonomización de la legitimación en la modernidad. Además, tampoco es necesario adoptar su interpretación de que si la secularización significa una base heteronómica de la modernidad, esto deba necesariamente identificarse como una 'desviación' o simple 'sustitución', ni mucho menos como una 'religión' de aquellos que justamente la niegan (Blumemberg, 2008, p. 115).

Por su parte, la teología política de Schmitt intenta precisamente desmentir, desde la perspectiva jurídica, la posibilidad misma de lo propuesto por Blumemberg, respecto a que legitimación y secularización puedan separarse, y que esta y aquella puedan entenderse independientemente de la estructura de pensamiento anterior. En cambio, Schmitt acepta la realidad del secularismo y al mismo tiempo piensa la posibilidad de irrupción de un tiempo nuevo en la historia. Si esto llevó a Taubes a pensar en Schmitt como un "apocalíptico desde arriba", vale pensar en contraposición a esta opinión el pensamiento de Schmitt desde el punto de vista gnóstico (Taubes, 2007, p. 169).

El katechon no es solo la estructura que permite mantener una fidelidad al mensaje en vistas de la tardanza del fin, sino que es también la tarea de la Iglesia de "detener al anticristo" (Schmitt, 1950, p. 16). Pero ante una época que elimina la condición necesaria de la experiencia monoteísta, esto es, algún tipo de trascendencia desde la cual juzgar al saeculum, se produce la secularización de 
dicha condición. Esto conlleva para el gnosticismo que ya no pueda haber una negación del mundo corrompido a partir de otra realidad que siempre permanece trascendente $-\mathrm{y}$ a la cual se hubiera podido huir en un gnosticismo monoteísta-, sino que solo queda encontrar la división y avanzar sobre esa negatividad en el seno del mundo, reemplazando el eschaton-que permanece siempre irrealizado a nivel mundano- por algún tipo de realización, como las que el propio Schmitt identifica en la era del cientificismo y capitalismo (Schmitt, 2009, pp. 132-33). Lo importante para notar aquí es que el propio Schmitt da pie a esa visión no escatológica, al tomar como realización universal de la administración del tiempo a la Iglesia que se vincula con los poderes y así permanece en el tiempo. Ante la posición agustiniana de las dos ciudades coetáneas, que responde a la parábola evangélica de la coexistencia de trigo y cizaña, la posición de esta teología política y su inspiración gnóstica en una era secular indica avanzar sobre la diferencia. Por ello, la tesis de Manemann (2002) es importante: no se trata en Schmitt del totalitarismo de un monoteísmo que niega la diferencia -ya que el monoteísmo precisamente abona la idea de la coexistencia en vistas de una trascendencia desde la cual juzgar, pero que siempre permanece allende el tiempo y toda concreción institucional-, sino de un 'gnosticismo antimonotoeísta'.

¿Qué sucede, entonces, con la 'nueva' teología política? Si en verdad la gnosis apunta a la aniquilación o negación del otro-enemigo, y si esto es realmente una acentuación del dualismo gnóstico que conduce a diversas totalizaciones de la organización social (siendo la de Schmitt solo una de ellas, acotada a las décadas de 1930 y de 1940, pero estructuralmente proyectable a otros fenómenos más contemporáneos de homogeneización forzada), ¿cuál sería la relación actual de la teología política con ese germen gnóstico en su estructura? Una respuesta posible es que la relación no es ni más ni menos que la antigua tensión, en el monoteísmo en general y en el cristianismo en particular, en cuanto a abordar los problemas del mundo motivados por las convicciones religiosas mismas, sabiendo que al hacerlo se produce necesariamente una 'negociación' entre esas convicciones y lo pragmáticamente viable. Por ello, es posible encontrar esa relación menos en la vertiente de teoría del Estado o del poder que en la elaboración teológica misma (Metz, 2007, p. 246).

Hubo una recepción de la teología política, particularmente en Estados Unidos, que la transformó en modelo para la imposición de una cosmovisión, una estructura económica, una política internacional y una serie de valores, en especial a partir de la lectura de Leo Strauss y sus seguidores (Strauss, 1997, pp. 1-84). ${ }^{1}$ Pero

Hay que señalar que esta no fue la única ni la más extendida visión de la relación entre lo religioso y lo político en Estados Unidos. Se encuentran otras líneas anteriores e influyentes, como el denominado 
hay otra recepción distinta, que ve los procesos producidos desde la Ilustración y su vínculo con las relaciones religiosas y su influencia en y desde la experiencia religiosa, que ni es apologética de ninguno de estos aspectos, porque no niega las tensiones producidas, pero que toma la posibilidad de transformación precisamente por esas tensiones; más aún, lo hace desde el punto de vista de las víctimas de todo este proceso. En este sentido, es significativo el subtítulo mismo del texto de Metz, Memoria passionis. Una evocación provocadora en una sociedad pluralista (2007).

La teología política así entendida no admite el dualismo privado-público característico de una Modernidad, pero tampoco acepta los integrismos o las injerencias inadmisibles de otra. Por el contrario, mantiene que las opciones de fe son personales y legítimas en su variedad, pero que en lo atinente a la opción cristiana, esta apoya al mundo en su positividad viendo, al mismo tiempo, las víctimas que tanto los procesos políticos como los religiosos produjeron. No niega la secularización producida y la imposibilidad de apelar de modo transversal en una sociedad a garantías o legitimaciones trascendentes, pero sí recurre a la memoria instaurada por el monoteísmo con sus características de responsabilidad por el prójimo y por las víctimas, para juzgar los resultados de las prácticas e instituciones históricas. Y lo notable es que no lo hace desde un tipo de conocimiento o dogma, o de algún tipo de experiencia iniciática, sino recuperando el valor de la narración y de las existencias personales y grupales. Aparece así, paradójicamente, como un tipo de trascendencia que no niega ni autonomía ni legitimidad a la historia (Metz, 2007, pp. 239-45). Esta teología política se encuentra equidistante tanto de Schmitt como de Voegelin, pues los dos juzgan la Modernidad de un modo negativo por no hacer lugar a la trascendencia -o 'realissimum' en lenguaje de Voegelin- en su configuración, mientras que para la teología política actual - tanto en Metz como en sus lectores- la Modernidad es relevante y necesaria en aspectos tales como autonomía y responsabilidad subjetiva y acceso a bienes que reubican lo trascendente en un mundo posmetafísico. Más aún, y como se analizará sobre el final de este trabajo, la visión situada de las teologías políticas latinoamericanas, piensa que un acceso -crítico pero acceso al fin-a la Modernidad es condición indispensable de posibilidad de algunas de las demandas más caras al cristianismo.

movimiento del 'social Gospel', o evangelio social, y la crítica a este por la escuela surgida de Reinhold Niebuhr y su 'realismo cristiano', que mantiene un dualismo de pertenencias y un reconocimiento de las tensiones, sin caer en el realismo excesivo de Lutero y Hobbes (Cavanaugh, Bailey y Hovey, 2012, pp. 217-67). Una lectura actual y crítica de la estructura norteamericana realizada desde la 'disciplina' requerida para los cristianos en vistas de los compromisos exigidos por el Estado norteamericano puede verse en Hauerwas $(2000,2013)$. 


\section{La recepción del problema religioso-político en Voegelin}

A pesar de los cuidados y condiciones con que se formula la propuesta de la teología política actual, probablemente esta también sería sometida a crítica por Voegelin, por ejemplo, en tanto el acceso al punto de vista de quienes han sufrido en la historia las consecuencias de toda práctica política, económica, social o religiosa, o sea el punto de vista de las víctimas, requiere un tipo de transformación interna que podría argüirse como conocimiento transformador, y al mismo tiempo que esa transformación interna se impone como mandato de transformación de las estructuras sociales. Aunque estos argumentos se retomarán más adelante, vale aquí señalarlos como síntoma de la desconfianza que le provoca a Voegelin el vínculo entre lo religioso y lo político, y la persistencia del gnosticismo en el mismo.

Desde temprana edad este autor advierte un problema central en el vínculo de la actividad política con las experiencias ligadas a lo religioso. En 1938 publica en Viena Las religiones políticas, en el marco del surgimiento del nazismo y el avance del socialismo soviético. La clave de lectura no es la de Schmitt, vale decir, que toda estructura de legitimación en la era secular tiene la misma estructura derivada del cristianismo católico, ni tampoco realiza una descripción sociológica respecto a que esos movimientos asumen aspectos como creencias, prácticas rituales, pérdida de espíritu crítico y masificación, características de muchas experiencias religiosas, sino y fundamentalmente porque se trata de un modo particular de comprender lo religioso, que luego en su obra identificará de modo explícito con el gnosticismo: un modo voluntarista de activismo y transformación de la realidad según el 'conocimiento' de un patrón o modelo de realización, que frente al fin o apocalipsis de un mundo malo puede gestionar su radical reconstrucción. Los autores que Voegelin identifica como constructores de este modo de pensar la actividad intramundana son precisamente los mismos que luego en su obra posterior denominará explícitamente gnósticos. Ellos apuntan además a pensar el propio Estado como religión o iglesia, donde se identifica claramente la separación de bien y mal, y se opera consecuentemente. Más aún, todo esto se construye con un mito que genera la unidad y la esperanza soteriológica de los miembros de una comunidad (Voegelin, 2000a, p. 62).

Cabe abordar la cuestión recordando que ya Hegel ponía en cuestión a su época, que olvida que el Estado descansa sobre un sentimiento ético, y este a su vez sobre el religioso, y que el intento moderno de desvincularlos condujo no solo a una mala comprensión de estos fenómenos, sino al fracaso de las políticas vinculadas a los mismos. En su análisis del laicismo francés y su intento de desvinculación, Lefort (2006, p. 158) reconstruye los logros de esta separación, pero al mismo tiempo esta 
escisión de prácticas y de sentidos, al ser sometida al análisis filosófico, muestra un 'apego continuo del filósofo a lo religioso': el filósofo recuerda que una sociedad que descansa sobre una pura autoinmanencia olvida el locus de la filosofía, y el vínculo de toda institución con aquello de lo que no se tiene la clave. La filosofía puede y debe una y otra vez hacer su crítica de lo religioso -y de lo político-, pero no parece posible ni deseable so pena de eliminar un aspecto insoslayable de la realidad, dejar de lado esa experiencia. Voegelin es un buen ejemplo de esto, en tanto no solo no niega, sino de hecho adhiere a una experiencia religiosa, afirma un modelo político, critica las posiciones alternativas e incluso propone una forma de vinculación entre ambas que considera legítima. Todo ello sin negar el fenómeno, y sin siquiera pretender su superación.

Para Voegelin, toda la época que va desde la Ilustración hasta el siglo XX puede denominarse la 'era gnóstica'. "La modernidad se define como el crecimiento del gnosticismo" (Voegelin, 2000a, p. 196); y luego amplía su definición: "materialismo económico, biología racista, psicología corrupta, cientificismo y crueldad tecnológica - en síntesis, modernidad sin límites" (Voegelin, 2000a, p. 241). Describe así este filósofo alemán un arco que va del gnosticismo a los peores eventos y nociones de la modernidad, y se muestra de modo irrestricto en su época. Todo esto se liga a una comprensión secularizada del mundo que no hace otra cosa que buscar reemplazos y alternativas para satisfacer la necesidad humana -personal y social- de encontrar modos de dar significado al mundo y a las propias acciones, así como también buscar modos de legitimar las decisiones. Por eso en su texto de 1938 la separación moderna de órdenes -privado-público, religioso-político, etc.- incapacita tanto al reconocimiento de que todo orden político ha sido justificado y legitimado por estructuras y narraciones simbólicas, como también hace difícil la crítica de los órdenes simbólicos que conllevan injusticia o que ubican a la propia estructura política en un orden más amplio de cosas con consecuencias moralmente inadmisibles. Es decir, hay un modelo de relación de lo religioso y lo político que aparenta mantener la escisión de ambos campos, cuando en realidad los reúne de modo peligroso mediante una comprensión estructuralmente gnóstica.

Voegelin comienza afirmando que toda conceptualización es posterior a las instituciones y los símbolos que las fundamentaron (2000a, p. 27). El avance del Estado como órgano no solo burocrático de ordenamiento social, sino también pasible de una 'creencia' por parte de sus ciudadanos, toma de la religión el "sentimiento de dependencia" característico de las religiones (Voegelin, 2000a, p. 31). Lo que sucede es que los símbolos religiosos son el modo en que cada época descubre el 'realisssimum', que se va plasmando de modo diverso. Esta idea de lo real es esencial para comprender todo el pensamiento de Voegelin. Cada época 
ha dado a luz instituciones y las ha nutrido de significados propios, pero a través de toda la historia hay una secuencia de "niveles de ser" o "verdades comunes" trascendentes a esas realizaciones y significados (Casanova 1997, p. 127). En la inmanencia de los procesos históricos demuestra una tensión hacia el orden, que se expresa simbólica y políticamente mediante diversas caras, pero con un mismo trasfondo. A pesar de sus analogías estructurales, esto no sería para Voegelin gnosticismo, pues no asumiría el 'totalitarismo' o imposición que le es característico a este. En cambio, es en el vínculo de lo político con lo religioso donde se tergiversan las funciones de ambos, como sucede, por ejemplo, en el Imperio romano y la progresiva simbolización del emperador como Autokrator, dando a luz a la primera religión política intramundana sobre una base cristiana (Voegelin, 2000a, p. 50). En paralelo al avance de estas estructuras, surgen los movimientos gnósticos contrarios, que de modo apocalíptico ligan apariciones de liderazgos, nuevas religiosidades y críticas al poder establecido. Mientras el poder político-religioso gnóstico buscaba un modelo social de perfección liderado por un hombre fuerte, las apariciones religioso-políticas gnósticas buscaban una perfección alternativa, espiritualizada, también guiada por un hombre fuerte e inspirado.

$\mathrm{Al}$ inicio de la Modernidad se produce según Voegelin una radicalización del proceso, como se ve en el Leviatán hobbesiano. El rango de lo temporal se pone al nivel de lo espiritual, y la Iglesia es una herramienta estatal. Así se eliminan dos factores claves para la experiencia cristiana. Por un lado, la libertad de conciencia deja de tener legitimidad en tanto atente contra la unidad estatal. Por otro, toda la experiencia de mediación o vicariato es eliminada en pos de una relación directa de los individuos con el Leviatán estatal. Con el advenimiento de la ciencia moderna, todo este conglomerado político-científico-religioso asume la tarea prometeica del progreso o mejora continua de la humanidad. Es notable que incluso entre los positivistas se gestan nuevos mitos y usos del símbolo: "Este no es abandonado por el hombre político-religioso; en cambio, el símbolo mantiene su capacidad de unir a las masas, aún cuando no alcance estándares científicos" (Voegelin, 2000a, p. 62). Las experiencias nacional-socialistas y fascistas son un ejemplo extremo de esta vinculación entre 'mito' y 'ciencia', como supuestos emergentes de un 'espíritu objetivo', es decir, realissimum, que abarca todo el período y se encarna en un líder.

Hay un último dato a tener en cuenta. La religión-política demanda siempre fe o creencia. Voegelin entiende que la experiencia religiosa se liga a la experiencia política cuando esta genera fervor, despersonalización y unidad entre los miembros de un grupo, y todo al mismo tiempo. Y la creencia se liga con el sentimiento profundo de una necesidad de salvación y de unidad con el todo. Así, lo político 
y el pueblo dejan el orden profano. En las conferencias que más tarde pronuncia a inicios de los años cincuenta, publicadas como La nueva ciencia de la política y editadas en el volumen 5 de sus Collected Works, Voegelin retoma estos dos aspectos precisamente: el desencanto operado por la Modernidad y los modos de representatividad política que esta generó. Esto es fundamental, porque la dificultad de toda legitimación política es ligar lo procedimental o formal con el vínculo existencial.

\section{La 'nueva ciencia política' ante el gnosticismo}

Al igual que otros pensadores de la 'revolución conservadora' de la posguerra que critican por igual los movimientos masivos de derechas que condujeron a la Segunda Guerra Mundial y las posiciones surgidas del 'socialismo real', Voegelin considera que la ciencia política está en pobres condiciones para dar respuestas a las necesidades de la época. Por un lado, estiman que los movimientos más influyentes que captaron la adhesión de millones de personas llevaron a estas a la barbarie; por otro, piensan que el liberalismo norteamericano -tierra donde se reagruparon en la posguerra muchos de esos pensadores, en especial provenientes de Alemania-adolece de problemas antropológicos y prácticos que causan la falta de compromiso y cohesión social. De hecho, en el caso de Voegelin, su análisis crítico de la Modernidad a partir del gnosticismo le valió la crítica de 'conservador' por parte de muchos de sus seguidores liberales, y al mismo tiempo, al volver a Alemania una década después, nunca ser aceptado por los círculos progresistas a pesar de sus sólidas credenciales antiautoritarias. En línea con esto, Arendt, por ejemplo, considera importante la obra de Voegelin, aunque en el camino equivocado (Voegelin, 2000a, p. 3). La propuesta de Voegelin es, en primera instancia, adoptar un método aristotélico que prevenga de las desviaciones ideológicas que el gnosticismo abona. En segundo lugar, afirma que hay tres tipos de verdades -cosmológicas, antropológicas y soteriológicas- que se manifiestan a lo largo de la historia, y que el aporte de la ciencia política debe ser alcanzar su máximo de diferenciación, so pena de recaer en diversos modos de nihilismo (Voegelin, 2000a, p. 152). Para ello, el procedimiento aristotélico permite distinguir los conceptos teóricos y los símbolos que son parte de la realidad, de la realidad misma: "en la transición de la realidad a la teoría deben definirse bien los criterios empleados en el proceso de clarificación; en la transición de la realidad a la teoría el valor cognitivo de los conceptos resultantes debe ser testeado, ubicándolos en contextos teoréticos más amplios" (Voegelin, 2000a, p. 112). 
La referencia a Aristóteles es relevante, porque es un correctivo ya de quien Voegelin considera origen esencial de la teoría filosófica política, Platón. Platón también corre el riesgo del activismo idealista característico de los gnósticos, y ese es el punto de partida de la crítica aristotélica (Voegelin, 2000b, p. 347). El 'ojo contemplativo' de Aristóteles 'contempla' no un mundo ideal, sino la realidad misma en sus relaciones pragmáticas, y desde allí descompone la 'voluntad creativa' de Platón. Voegelin identifica como problema en Aristóteles la carencia de un sistema claro de la ciencia política, pero al mismo tiempo identifica el valor de relacionar la política con el desarrollo personal de los ciudadanos: "el fin (telos) de la ciencia política es el bien del hombre", y este bien es el mismo que el bien de la polis: la eudaimonia (2000b, p. 349). La ciencia política debe dividirse, entonces, en ética y política, y debe partir de la descripción antropológica de los modelos de relación establecidos, sus límites y sus posibilidades en vistas de ese fin. Y como la lógica de acción debe tener en cuenta al ser humano y su relación con los hábitos, siempre lenta y progresiva, también esto tendrá un impacto en el realismo necesario de las prácticas y voluntades políticas. Por eso Voegelin recupera el valor de Aristóteles a la hora de analizar los modelos políticos de su época, que a menudo pretendieron el acceso al poder, a la aquiescencia y a la representatividad de los individuos, teniendo en cuenta un fin, pero sin pensar en el procedimiento y factibilidad, como tampoco en la realidad persistente de lo que simbólicamente pretendían exponer e imponer.

Desde el punto de vista histórico, uno de los mayores orígenes de las luchas entre colectivos e instituciones es la lucha por la representación. En el caso concreto del Occidente cristiano, la lucha es por la obtención y el reconocimiento de la representación pública de la verdad trascendente (Voegelin, 2000a, p. 153). Junto a esa lucha surge un segundo conflicto: cómo hacer al gobernante reconocer la verdad divina, cómo hacerle actuar de modo acorde y cómo corregirle en caso de desviación. No es aquí el lugar para un análisis detallado de la reconstrucción de Voegelin del principado y el patronato romanos, sino solo vale afirmar que la verdad no funciona socialmente sin adhesión, y que estas instituciones lograban obtener de sus 'súbditos' la adhesión existencial de una representación genuina. La relación con el cristianismo no solo es tensa por la divergencia de dioses o el problema de la adhesión a los fines estatales por parte de los cristianos, sino que la verdadera revolución cristiana estaba en su incompatibilidad con el paganismo, en tanto el cristianismo significaba una "radical desdivinización del mundo" (Voegelin, 2000a, p. 169). Por ello se entiende, por ejemplo, que la verdadera crítica de Celso al cristianismo sea en razón de su 'paganismo', en tanto deja al mundo solo mundo -aunque sea en una relación histórica con Dios. A pesar de 
todo lo que se afirma sobre secularización y desencantamiento del mundo -por ejemplo en Weber, Blumemberg y Marquard-, Voegelin considera que uno de los orígenes de los problemas modernos se da con la redivinización de la sociedad y la caída de la doble representación -eclesial e imperial- que se proyectó durante toda la Edad Media.

La victoria del cristianismo significó la desdivinización de la esfera temporal del poder (Voegelin, 2000a, p. 175). A pesar de todos los intentos de justificar y reasumir la condición divina por parte de los gobernantes, el cristianismo ha supuesto siempre una progresiva secularización del poder estatal. Por su parte, los diversos intentos simbólicos y conceptuales de la Modernidad para dar sentido a la relación de los ciudadanos con el Estado están marcados por la genealogía del cristianismo: la tensión intracristiana con el judaísmo y la apocalíptica que le es propia. La respuesta agustiniana de ver a las dos ciudades entremezcladas -y la identificación del Reino en la Iglesia- es también conmovida por la expectativa revolucionaria de la nueva venida mesiánica (que el agustinismo fue espiritualizando y convirtiendo en asunto de conversión privada en el interior de los sujetos). Así se identifican en emergentes históricos considerados heréticos, como por ejemplo, Joaquín de Fiore; estructuras comunes apocalípticas, como por ejemplo la idea de que la historia es una secuencia de eras, que cada una de ellas es 'encarnada' por un líder, y que a este líder se le anticipa un 'profeta' que conoce el sentido de la historia, y que este movimiento coagula en una hermandad de pensadores autónomos capaces de autotransformación y de transformación de las estructuras sin otra fuerza o gracia que la de sus propios esfuerzos. Este es el rol especulativo-práctico del "intelectual gnóstico" (Voegelin, 2000a, p. 179).

Con el avance de la Modernidad sucede una inmanentización de este eschaton en la historia. La 'nueva' ciencia política debe identificar, según Voegelin, los tipos de gnosis involucrados en esta concepción teológico-política, como la gnosis intelectual, la emocional y la volicional. Y la característica transversal del modo en que operan es la redivinización de la sociedad y la autodivinización de las personas que participan de ellas. Esta estructura se ve en el desarrollo político occidental "del inmanentismo medieval hasta el humanismo, la Ilustración, el progresismo, el liberalismo, el positivismo y el marxismo" (Voegelin 2000a, p. 189). Estos son modos gnósticos de especular, que al caer el sentido de trascendencia intentan superar el problema de la incerteza o falta de fe concediendo al ser humano y su acción intramundana el sentido de una realización escatológica de autorredención. Voegelin ve de modo claro que un resultado visible de este gnosticismo son los puritanismos y sus consecuencias, siendo la más visible la prohibición de toda crítica (Voegelin, 2000a, p. 202). 
Finalmente, algo ante lo cual el realismo aristotélico -que Voegelin afirma metodológicamente sostener- es muy sensible y crítico, es la idea de que las transformaciones apuntadas no son reformatorias, sino transformadoras, revolucionarias. La idea gnóstica por detrás es que toda esta actividad antrópica gnóstica cambiará la naturaleza del hombre y establecerá una sociedad transfigurada y perfecta (Voegelin, 2000a, p. 211). Esta sería una de las fuentes de justificación de la 'ley natural' en la Modernidad temprana, que se buscó siempre identificar con la voluntad divina y su autoridad. De este modo, la ley y la sociedad misma tienen una trascendencia-inmanentizada, una existencia natural-trascendental que el cristianismo siempre le negó. En cambio la Modernidad asumió esta relación y dio lugar, en la peor de sus versiones, al totalitarismo (Voegelin, 2000a, p. 221). De esta manera, la tarea de la ciencia política es desenmascarar la falta de realidad del gnosticismo, de su teología civil, y la autoderrota a la que esta relación conduce. Ante esta descripción del desarrollo histórico, la tarea de la nueva ciencia de la política es "exorcizar los demonios en la modesta medida de la efectividad que nuestra sociedad le concede a la episteme y su terapia" (Voegelin, 2000a, p. 277).

\section{Gnosticismo religioso, gnosticismo filosófico y gnosticismo político}

Se le ha criticado a Voegelin un uso tan amplio del apelativo crítico 'gnóstico' porque engloba pensadores y movimientos en extremo disímiles y cambiantes (Manemann, 2002, p. 64). Si bien es válido y útil para el pensamiento poder identificar analogías o estructuras comunes, la crítica no debe ser pasada por alto. No en pos de refutarla ni de argumentar en favor de Voegelin, pero sí de establecer el sentido que el término admite, conviene identificar los sentidos con que el término se usa en su aplicación al campo religioso, al filosófico y al político. Un movimiento esencial para el gnosticismo, en términos de Voegelin, es inmanentizar el sentido de la existencia, de considerar el mundo como negativo, y de considerarse en posesión de un conocimiento capaz de transformar radicalmente al mundo en su inmanencia.

Voegelin ve que la historia del gnosticismo, en su influencia política, nace en el cristianismo y como herejía. Aquí el vínculo con lo religioso parte no de una convocatoria o vocación, ni de un mensaje existencial, como sucede a menudo en las religiones, sino con la insatisfacción con la situación propia, y con la idea de que el mal y la negatividad del mundo se deben a una mala organización del mismo o a su maldad intrínseca. A esta idea se suma otra importante: la salvación de este mal es posible, y que el orden del ser puede cambiarse en un proceso histórico por 
la acción humana que, ante todo, implica un modo de conocimiento (Voegelin 2000a, pp. 297-98). El gnosticismo se convierte ante todo en una ersatz Religion o 'religión sustituta', ante todo en el seno mismo de la religión. Y es 'sustituta' porque anula un componente indispensable para la religión en la concepción occidental, es decir, toda relación con la trascendencia. Esta religiosidad, en cambio, opera tres tipos de inmanentización: se inmanentiza el telos mediante la noción de un progreso histórico, se inmanentiza la axiología por la pretensión de una transformación radical del orden social en el tiempo, y finalmente se da un misticismo activista que liga a los dos elementos anteriores mediante la fe en un estado de perfección propia (Voegelin, 2000a, p. 300).

En tanto religión sustituta, el gnosticismo toma elementos centrales de la religión monoteísta, pero opera una transformación inmanentista. Esta transformación no carece de vínculos con el monoteísmo, ya que las religiones surgidas de esta doctrina siempre se consideraron relacionadas con la historia por origen y compromiso moral. El problema es el paso sin mediaciones entre los niveles simbólicos y de realización. Es importante notar que la figura del 'profeta' y del 'líder' que anuncia el cambio de era y lo lleva a cabo, se manifiesta ante todo en el campo religioso -como Joaquín de Fiore-, pero rápidamente es asumida por los filósofos. Voegelin reconstruye, ante todo, los casos de Moro, Hobbes, Hegel y Marx. La inmanentización de la idea cristiana de perfección y la identificación de un rol representativo formal y existencial en el Estado lleva a estos pensadores a un giro gnóstico en la filosofía. Lo característico en estos pensadores es que en cada caso se "suprime un elemento esencial de la realidad para ser capaz de construir una imagen del hombre, o de la sociedad, o de la historia, que concuerde con sus deseos" (Voegelin, 2000a, p. 309). La utopía que niega el proceso de la realidad y asume que la perfección es históricamente posible; el Leviatán estatal que se asume como único representante sin mediadores y gran censor de aquello que atente contra la unidad estatal; el Espíritu Absoluto que realiza en forma dialéctica su voluntad en la historia, independientemente de las particularidades; y por último, la sociedad comunista realizada que prohíbe la pregunta y fuerza una realización imposible, son todos ejemplos en los que Voegelin ve a la filosofía como propuesta gnóstica.

No es solo esta estructura general la que lleva a Voegelin a identificar como gnósticos también a Nietzsche y Heidegger, sino aspectos mucho más definidos. Hacer al mundo según sus propios deseos es, para Voegelin, el mensaje esencial de la filosofía nietzscheana, lo que para él constituye una continuación del gnosticismo. Nietzsche propone una periagoge, la apertura del alma, pero sin trascendencia y con voluntad de dominio y de configuración del mundo a voluntad. Para ello debe negar un aspecto de la realidad, que comienza con su propia limitación e 
impotencia. Por eso: "mandar significa ser Dios; para ser Dios el hombre gnóstico toma sobre sí los tormentos del engaño y la autolaceración" (Voegelin, 2000a, p. 266). La muerte de Dios, que debía dar lugar al superhombre que canalice la autocreación poiética subjetiva, acaba en realidad con la muerte del hombre. El superhombre aparece como figura gnóstica una y otra vez, y la capacidad de creación de los propios valores sin dependencia alguna -ni de Dios ni de la realidad-es la manifestación gnóstica que une a Nietzsche con Marx (Voegelin, 2000a, p. 303).

En el caso de Heidegger, la 'condición de arrojado', Geworfenheit, coincide con el pensamiento gnóstico del mundo como lugar ajeno y el deseo de retorno a un espacio genuino (Voegelin, 2000a, p. 254). El existente se da en una facticidad, está ahí, sumido en la existencia y habitualmente caído en un modo no genuino de ser. Asumir sus posibilidades significa partir de este "estar entregado a sí mismo" (Heidegger, 1997, p. 139) y lograr el cuidado del mundo que le lleve a su esencia. Para Heidegger el mundo vive un período de existencia no-esencial, en que el ser ha sido oculto o se manifiesta en modos como la técnica, que solo proponen una disposición 'a la mano' del ser como ente. A diferencia de los demás filósofos, Heidegger no propone una visión entificante o concreta de la realización esencial, sino un modo de salvación en que el conocimiento a menudo acaba en el silencio.

\section{Una mirada crítica de la crítica voegeliniana}

La noción de realissimum o realidad trascendente, que según Voegelin es interpretada y simbolizada a su modo por cada época, dando resultados en mayor o menor medida pertinentes según la proximidad a esa realidad, indica ya una noción metafísica que requiere de cierta 'contemplación' difícil de aceptar en una era en la que una importante parte de las comprensiones metafísicas han caído. No solo es metafísico por su cercanía con una noción de 'naturaleza' cercana a la aristotélica (Voegelin, 2000b, p. 369), sino también porque su filosofía es "menos fenomenológica y más revelatoria" (Petrakis, 2004, p. 53). Sin embargo, atacar a Voegelin por metafísico en una época en que la metafísica es a menudo presa fácil como epíteto y por falta de seriedad en la crítica, sería simplemente una banalización intelectual del argumento. Un segundo abordaje crítico, menos banal aunque igualmente poco fecundo, es aplicar a Voegelin su propia crítica del gnosticismo, porque pensar en el gnóstico como aquel que posee el 'conocimiento' de una estructura de mundo, que las instituciones luego deben realizar, no difiere mucho de la 'contemplación' requerida por Voegelin en su recepción de Aristóteles. Esta contemplación sería precisamente lo que evitaría los demás riesgos gnósticos, pero 
también lo que permitiría la realización de una sociedad feliz, o sea, aquella en que el mismo bios theoretikos pueda realizarse (Voegelin, 2000b, p. 371). Ambas objeciones son viables, pero conviene ejercer una crítica desde otra perspectiva.

Un punto de partida crítico más interesante para analizar la propuesta de Voegelin sobre lo religioso político se halla en La estrella de la redención (1997) de Franz Rosenzweig. Con una propuesta esquemática y anterior a la Shoah, con todo lo que esto significa, Rosenzweig estudia el rol del cristianismo y del judaísmo en la historia bajo el título de "política mesiánica" (Rosenzweig, 1997, p. 389). Aquí ve cómo todo pueblo se ha pensado a sí mismo a partir de la salvación propia y la fidelidad a sí, y cómo debido al cristianismo la idea de elección propia del judaísmo es asumida por pueblos particulares, que luego la utilizan en su relación con otros pueblos particulares (Rosenzweig, 1997, p. 391). Pero es el pueblo judío el que, debido a su ubicación ya en la meta, no se toma la guerra en serio, desmiente su supuesto rol salvífico, y pone límites a la creencia en el Estado que alcanzará esos bienes para un pueblo. Frente a esta disposición estática, que es estable y corre paralela al desarrollo histórico, aparece el otro camino, el de la fe cristiana que crea siempre al mundo, intenta convertir y transformar a este en vistas de su concepción del bien. Y sin embargo no subsume bajo una totalidad, como sucede en el mundo griego, porque "en la $\kappa \kappa \lambda \varepsilon \sigma \alpha$ " el individuo es y permanece individuo; sólo la resolución es común, y se convierte en res publica” (Rosenzweig, 1997, p. 406). El judaísmo es eterno porque abarca ya en sí todos los grandes opuestos; también sucede eso en el cristianismo, pero de un modo aún inconcluso y por tanto de camino. Es notable que la complexio oppositorum también es la tarea característica que Schmitt identifica en el cristianismo católico (Schmitt, 2011, p. 10), pero mientras para él de lo que se trata es de eliminar esa tensión con una instancia superadora, la propuesta de Rosenzweig, ciertamente metafórica y con todos los riesgos que eso implica, es acceder a una verdad coral, donde todas las voces al mismo tiempo son únicas, pero con un canto común (Rosenzweig 1997, p. 282). Más aún, esta tarea no puede acabarse sub specie temporis, porque el Reino "siempre es futuro; pero es futuro siempre" (Rosenzweig, 1997, p. 277), lo que significa que el Reino solo puede crecer no solo si no se lo identifica con un modelo institucional determinado, sino también si se evita hacerlo homólogo a nociones como avance o progreso, que 'emponzońan' la noción de futuro esencial para el Reino y su crecimiento (Rosenzweig, 1997, p. 275).

Voegelin acordaría con la crítica a un progreso comprendido como inmanencia salvífica en que lo trascendente y la salvación se dan en la historia sin separación. Lo difícil en el caso de Voegelin es ver por qué alguien se vería motivado a obrar así, problema análogo al que, como se formuló antes, Hegel vio en el Estado moderno. 
De hecho, uno de sus problemas es no caer en el liberalismo, cuyo nihilismo está dado justamente por la negativa a aceptar la legitimidad de una comprensión de la realidad imponible a las libertades individuales, lo que redunda en la imposibilidad de una comunidad (Jardine, 2004, p. 61). Desde esta perspectiva, las tradiciones religiosas surgidas del monoteísmo implican un modo de comprender el mundo como deber de justicia, igualdad, fraternidad, y al mismo tiempo como respeto por la dignidad de cada individuo como parte de una familia, que muestran a la vida social como mucho más que relaciones burocráticas eficientes. De alguna manera, la vida política sería preparar las condiciones para -utilizando términos religiosos- el 'Reino', sabiendo que este es solo ideal regulatorio, y que cada realización está en riesgo de ir contra ese ideal mismo.

En este sentido no es casual que en el período de la Modernidad tardía o posmodernidad se vuelva a pensadores cristianos, ya que fue el cristianismo el que, a pesar de sus construcciones cercanas al mundo griego, negó una y otra vez la idea de una realización apegada a una estructura previa (Jardine, 2004, p. 82). Tampoco es casual que pensadores que comprenden lo político como mucho más que el libre juego liberal de libertades autocreadoras, incluso no perteneciendo al ámbito religioso, se acerquen a este interesados por su estructura. Tal es el caso, por ejemplo, de Laclau (2006), cuando plantea que en una época posmoderna, que ve la contingencia de todo reclamo político o moral, se revela la 'sobreinversión' ética: "El compromiso moral serio requiere de una separación radical entre la conciencia moral y sus contenidos, de modo que ningún contenido puede tener a priori ninguna exigencia de ser el beneficiario exclusivo del compromiso" (Laclau, 2006, p. 147). Del mismo modo, en la construcción de lo político el compromiso religioso funcionaría como un modo de conciencia que demanda más allá de toda realización e incluso críticamente sobre cada realización. Si en ocasiones lo político se convirtió en un tipo de religión, esto no sucedió porque la religión se 'desvirtúe' como política, sino porque la religión siempre corre el riesgo de una entificación o idolatrización análogo al de la política y la ética.

En cuanto al gnosticismo en sentido estricto, el problema que atraviesa el planteo es que la noción de Voegelin no incluye algo transversal a todo gnosticismo: se trata de un conocimiento iniciático que, a diferencia de la ciencia y de la política, no es de público dominio, sino de acceso privilegiado a pocos. Incluso dando lugar a pensar que algunos de los filósofos indagados tuvieron una comprensión elitista de sus propias filosofías, tal el caso de Nietzsche, nunca se pensó que la misma tuviese ese rol iniciático de arcano. En esto, el cristianismo ha tenido siempre la principal arma para combatir el tipo de doctrina salvífica del gnosticismo: para el cristianismo ya se dio la salvación, incluso cuando deba realizarse epocalmente; y 
la expectativa de otra manifestación divina no es sino la esperanza de algo para lo cual el sujeto y la sociedad pueden prepararse, pero nunca causar.

Otra de las características de todo gnosticismo es su pesimismo cosmológico, la negación del mundo y de su bondad (Manemann, 2002, p. 53). Pero es preciso no confundir la idea del mal como connatural al mundo con la idea de que hay mal y este se ha dado por motivos ligados a la libertad humana, y que por tanto debe ser abordado y se le debe dar una respuesta. Desde esta perspectiva, el mal sí es una realidad y si hubo respuestas inadmisibles y estas gozaron de adhesión no solo por la sensación existencial de algo malo en el mundo, esto no se debió a una creencia metafísica de lucha entre dos fuentes 'divinas', sino por la materialidad de una existencia marcada por la injusticia, el sufrimiento, la menesterosidad, o incluso la falta de sentido, que a menudo llevó a quienes lo sufrían a buscar una respuesta 'idolátrica'. En todo caso, el problema es menos el dualismo gnóstico que la 'constitución idolátrica del ser humano', ante la cual la religión podría ciertamente servir como instrumento desmitificador y liberador. La novedad de la teología política contemporánea y su acento sobre las relaciones sociales y sus consecuencias inadmisibles es que no se piensa a sí ni a la historia desde una ortodoxia o desde una idea previa, como sucede con Voegelin, sino desde la 'evidencia' de los sufrientes como prueba de lo hecho mal en la historia y como reclamo transhistórico de justicia. El cristianismo permite un 'ateísmo' en el sentido levinasiano, vale decir, la negativa a 'creer' que las construcciones e instituciones históricas sean el Reino. Por tanto, la espera de otra cosa indica no una huida del mundo, sino la limitación de su sentido y la apertura crítica desde una serie de exigencias imposibles de satisfacer, pero imprescindibles como lugar desde el cual ejercer un juicio a la historia.

Mientras la Modernidad es para Voegelin una gnosis, para Blumemberg es una antignosis. En su comentario a Schmitt, Villacañas afirma que la tesis de Blumemberg es una salida contemporánea al gnosticismo, como lo fue el trinitarismo antes. Mientras el trinitarismo implicaba una lógica sacramental, el secularismo llevó a buscar instancias intramundanas para deificar al ser humano. Lo interesante es que esta propuesta, como se la ve en Cusa o Bruno, no vinculó al Estado con su teología política, sino con los resultados de la ciencia moderna. Así, según Villacańas, Blumemberg enmienda toda la propuesta voegeliniana, ya que no formula la crítica a una 'modernidad sin límites', sino que argumenta la legitimidad de sus realizaciones como el mejor reaseguro contra el gnosticismo (Schmitt, 2009, p. 177). Aquí valdría retomar el pensamiento de Voegelin no ya en defensa de su teoría del orden en la historia, sino más bien de su idea de la acción de la filosofía como episteme y terapia respecto de la propia filosofía; en este caso, por ejemplo, 
las certezas de Blumemberg, pero argumentando por un lugar para lo religioso como prueba de lo que no es manejable por la ciencia y la filosofía, y como un tipo de demanda que supera sus posibilidades. Lo mismo cabe para los filósofos considerados por Voegelin como 'gnósticos', en tanto las analogías estructurales que este identifica parecen menos producto de un pensamiento gnóstico que de la identificación de genuinos déficits de la filosofía moderna, tal es el caso de la necesidad de construir valores por la caducidad de los tradicionales y la condición de caída en Nietzsche y Heidegger. Por eso, frente a críticos como Blumemberg, que basan su ataque en la noción de 'legitimidad' de la Modernidad, vale decir que ni Voegelin ni los autores teológico-políticos contemporáneos de fines del siglo XX y principios del XXI reniegan de dicha legitimidad. Voegelin caracteriza el trabajo filosófico como una mediación de la trascendencia, y por lo tanto su estudio de la conciencia humana como intencionalidad, luminosidad y distancia reflexiva, como aquel marco en que se debe dar la conciencia de y apertura a la trascendencia, muestra que efectivamente el eje de su análisis del secularismo reside en la incapacidad de este de abrirse a los símbolos y verdades que le antecedieron. De ninguna manera, no se trata de que Voegelin reniegue de la modernidad. En todo caso, su propuesta es formular el marco y los límites de la misma. Algunas de las potencialidades de lo religioso-político en América Latina podrían servir precisamente a este fin.

\section{Aportes para otra relación religioso-política desde América Latina}

A pesar de la recepción relativamente limitada en América Latina de la obra de Voegelin, es en general más influyente la que se da en el campo conservador-liberal, es decir, la propuesta filosófico-política que con diversas formulaciones abreva, desde la perspectiva ético-política, en principios conservadores y, económicamente hablando, en principios liberales. ${ }^{2}$ Desde esta perspectiva, la lectura crítica que Voegelin hace de lo teológico-político serviría, por un lado, para alentar ciertas libertades de autorrealización económica, de limitación de la injerencia estatal y fuertemente combativas de toda propuesta socializante; por otro lado, intentaría renovar el valor de lo simbólico para la construcción de un modo de comunidad simbólicamente homogénea. Allí se hallan, paradójicamente, dos posturas ante la Modernidad: una reaccionaria, que entiende que la multiplicación de identidades y símbolos, así como la tecnificación y burocratización de la vida que caracteriza

2 Es de destacar en este sentido la tesis de Casanova (1997) y el importante rastreo bibliográfico que presenta. 
a las sociedades modernas conlleva una pérdida identitaria -como la que podría fomentar la religión-, y al mismo tiempo una ganancia respecto de las formas 'religiosas' y 'gnósticas', en el sentido de Voegelin de lo político.

Frente a esto, es preciso ante todo separar el gnosticismo que Voegelin identifica como voluntad de operar el eschaton en la inmanencia de la historia de la responsabilidad por la historia en vistas a convicciones respecto de la trascendencia. Y desde esta separación es viable pensar en una respuesta posible a la lectura de Voegelin que podría hacerse desde el campo conservador-liberal a partir de otra lectura de lo religioso-político, en particular aquella realizada desde las víctimas y los marginales del sistema como la entienden los liberacionismos teológico y filosófico.

La presencia todavía importante del catolicismo en América Latina es un claro síntoma de la tensión. A menudo la Iglesia, en especial la jerarquía, se asoció a propuestas nacionalistas capaces de asegurar una 'identidad' por su vínculo con el integrismo. Pero el mensaje monoteísta en general y cristiano en particular porta un mensaje profético importante por su interés en la liberación del pobre. Por eso fue diversa la reacción de la jerarquía ante las propuestas teológicas liberacionistas que señalaban metodológicamente la necesidad de ver, juzgar y actuar, y que la acción debía preceder al dogma -primado de la ortopraxis ante la ortodoxia. Y frente a diversos momentos y documentos referentes a la posición políticamente activa de la teología latinoamericana, Ellacuría (1999, pp. 272-85) explica el rol de la teología frente a lo social. Coincide con Sollicitudo Rei Socialis (1987): "Desde la perspectiva del análisis socio-político, del enjuiciamiento moral y del discernimiento teológico, aparece toda una serie de factores negativos, que son la negación de la razón, del hombre y del reino de Dios" (Ellacuría, 1999, p. 275). Es decir, no hay una teoría o una ortodoxia, de acceso previo cognitivamente hablando, sino que hay la identificación en la praxis misma de modos de acción y decisiones más o menos liberadores en vista de los resultados respecto de los 'negados' del mundo. Más adelante, Ellacuría (1999, p. 282) vincula esta negatividad no a una condición inherente o metafísica, aunque tampoco se vuelca a una noción de 'realidad' en sentido de Voegelin para aportar una propuesta superadora, sino que la negatividad está dada -teológicamente hablando- por el pecado, es decir, constituye un producto de decisiones históricas y libres que generaron una situación de opresión estructural, y la superación no está en otra negación de la realidad ni en la aniquilación del opresor, sino en la opción de asumir la perspectiva de los padecientes y pobres, y recién desde esa perspectiva utilizar todas las herramientas provenientes de las ciencias, la filosofía y la teología. El monoteísmo, entonces, sería el sesgo de esa opción.

El otro aspecto a tener en cuenta es el vínculo con la historia. Ciertamente, los movimientos sectarios apocalípticos poco contribuyen a pensar el valor de 
la apocalíptica para una teología política. En esto Voegelin apoya el sentido liberal de la historia sin ley, ni telos, ni utopía o Reino inspirador. La posición de Voegelin se acerca así, paradójicamente, a la de Schmitt, en tanto ve a la política como katechon o administración intramundana. La apocalíptica sería solo una concepción que violenta la evolución del orden progresivo en la historia. Esta afirmación tiene razón, vistas las cosas desde América Latina al menos, en tanto las estructuras religiosas no solo han sido conniventes y cómplices de regímenes de poder, sino también han sido irrupciones de actores negados de la historia, han mostrado el fin de la historia (en el doble sentido de acabamiento de órdenes legitimados y el de finalidad de un 'orden' -evangélico, por ejemplo- de la igualdad y fraternidad). Sin embargo, pensar que nada es 'mejor' -y por tanto 'peor'- históricamente hablando, termina siendo un conservadurismo connivente con situaciones de opresión. Lo que sucede aquí es que, en una lectura de Aristóteles, Voegelin 'privatiza' el mal, ya que no está en las cosas ni en las sociedades, sino en el deseo propio (Voegelin, 2000b, p. 376). En cambio, la responsabilidad por una demanda trascendente significaría una comprensión 'monoteísta' de lo político, que conjuga -no sin contradicciones- las demandas religiosas con las seculares. Es importante en este punto recordar la reconstrucción que Gutiérrez hace de los bosquejos de la primera parte de Gaudium et spes (1965), que al mismo tiempo recupera el agustinismo de la no-identificación de un orden social con el Reino, pero no es indiferente para el crecimiento del Reino que se opere realmente una mejora en las condiciones de vida de los ciudadanos (Gutiérrez, 1984, p. 232). Por eso, la liberación y construcción del mundo debe ser integral.

Por eso el 'secularismo' no debe ser comprendido solo como inmanentización. El 'desencanto' que Weber ve en los procesos de racionalización moderna puede ser acompañado por una visión religioso-política que es al mismo tiempo crítica y positiva. Crítica, en tanto identifica lo irracional e inhumano en tal racionalización; y positiva en tanto también el monoteísmo argumenta por una desmitificación, por ejemplo de los poderes, que ya no disponen de argumentos teológicos para su imposición y por lo tanto deben garantizar otros modos de aquiescencia para su legitimación. Es importante recordar también la importancia escatológica que tienen tanto la utopía en el sentido de Gutiérrez, como la memoria de la pasión en el de Metz como principios transformadores del mundo. Estos principios se consideran racionales, en tanto hay aspectos de la realidad política que de ese modo superan la inmanencia, y no serían posesión cognitiva o intuitiva de un grupo de iluminados frente a un mundo metafísicamente malo, sino la pasión que inspira a la razón a reconocer lo que aún demanda la responsabilidad humana. 
La crítica doble tanto a la religión-política como al secularismo, y la propia propuesta de Voegelin de retomar la 'realidad' más profunda en los movimientos políticos y religiosos, y en los símbolos a los que dan lugar, tiene la virtud de identificar los riesgos constantes de la relación que se identifica en la proyección política de deseos $\mathrm{y}$ anhelos que trascienden a la historia y sus posibilidades. Pero en una era posmetafísica es difícil aceptar el realissimum que Voegelin ve en y allende los procesos históricos. Por otra parte, los anhelos más vinculados con el eschaton, claves para toda teología política, no deben confundirse con su entificación en movimientos o momentos históricos concretos. Más aún, la posibilidad de lo religioso-político es proponer un motor de la acción pública que supera lo histórico, lo inspira y lo critica desde un ideal regulatorio que jamás se entifica en una institucionalización concreta. El profetismo, esencial a todo vínculo religioso-político, lejos de toda connivencia significa la crítica radical de toda realización, a la luz de un ideal de humanidad realizada que debe juzgar tanto los fines como los medios.

Nuestra época tiene una relación tensa con lo religioso. Por un lado aparecen violencias caracterizadas por la motivación o justificación religiosa, y como contrapartida se ofrece el antiguo remedio de una secularización sin restos de sacralidad o espacios simbólicos. Sin embargo, ambos extremos son difícilmente aceptables en América Latina. América Latina ha conocido diversos modos y modelos de 'modernidad', que a su vez se han enfrentado de diferentes maneras con sus propias experiencias de lo religioso. Si bien las experiencias han sido disímiles en los diversos países, cabe decir que la vieja discusión de liberales y conservadores, tan extendida en los períodos posteriores a las independencias y en las generaciones de fines del siglo XIX, así como los advenimientos de los movimientos de masas y sus discusiones con las corrientes europeas como los liberalismos y los socialismos, nunca pudieron escindirse de la sensibilidad religiosa de los pueblos latinoamericanos. Esta sensibilidad también debe matizarse, pues conoce extremos que alcanzan lo supersticioso, pero también se hallan sectores que intentan hacerse cargo de la modernidad, sin abandonar del todo las convicciones simbólicas y religiosas (Ortiz, 2013).

Desde esta perspectiva, hacerse cargo de la modernidad no significa caer en el orden gnóstico criticado por Voegelin, ni mucho menos absolutizar los resultados científicos y políticos de la modernidad. Por el contrario, las experiencias del compromiso religioso, expresado en clave teológico-política, suponen, ante todo, que es demasiado limitado entender la acción humana en clave de inmanencia. Esto es, que la experiencia religiosa genera modos de compromiso y responsabilidad que 
superan los límites de una época y comunidad histórica. Desde esta perspectiva no hay posibilidad de autojustificación o legitimación pragmática, sino que toda valoración se postula desde el rasero de los efectos de las decisiones en la vida de los más expuestos y débiles. Pero además, y más importante quizás, es el hecho de que la experiencia religiosa conlleva en sí también las demandas en pos de una humanidad más solidaria, igualitaria y justa. A diferencia de Voegelin, lo religioso en su vínculo con lo político no requiere de los compromisos metafísicos que Voegelin defiende, ni significa necesariamente, por otra parte, la recaída en un totalitarismo o integrismo. Es más bien un acicate para que lo político no olvide a las víctimas de todo sistema, y al mismo tiempo para que lo religioso no huya en alguna metafísica o justificación acrítica de la historia y se comprometa con las mediaciones necesarias de sus compromisos éticos.

Recibido noviembre 4, 2014 Aceptado noviembre 27, 2014

\section{Referencias bibliográficas}

Blumemberg, H. (2008). La legitimación de la Edad Moderna. Valencia: Pre-Textos.

Casanova, C. A. (1997). Verdad escatológica y acción intramundana. La teoría política de Eric Voegelin. Pamplona: Eunsa.

Cavanaugh, W. T., Bailey, J. W., Hovey, C. (2012). An Eerdmans Reader in Contemporary Political Theology. Grand Rapids: Michigan Eerdmans.

Concilio Vaticano II (1965). Constitución pastoral Gaudium et spes. Disponible en http://www. vatican.va/archive/hist_councils/ii_vatican_council/documents/vat-ii_const_19651207_ gaudium-et-spes_sp.html.

Ellacuría, I. (1999). Escritos universitarios. San Salvador: UCA Editores.

Fonti, D. (2009). ¿Una política monoteísta? Rosenzweig, Levinas y el Estado de Israel. Nombres. Revista de Filosofía, 23, 151-77.

González Faus, J. I. (2005). La constitución idolátrica del ser humano. En N.-G. Specchia y G. Morello, Idolatrías de Occidente (pp. 19-42). Córdoba, Argentina: EDUCC.

Gutiérrez, G. (1984). Teología de la liberación. Perspectivas. Salamanca: Sígueme.

Hauerwas, S. (2000). A Better Hope. Resources for a Church Confronting Capitalism, Democracy and Postmodernity. Grand Rapids: Michigan Brazos Press.

Hauerwas, S. (2013). Approaching the End. Eschatological Reflections on Church, Politics and Life. Grand Rapids: Michigan Eerdmans.

Heidegger, M. (1997). Ser y tiempo. Santiago: Universitaria. 
Ireneo de Lyon (2003). Lo mejor de Ireneo de Lyon. Contra las herejias. Demostración de la enseñanza apostólica. Barcelona: Clie.

Juan Pablo II (1987). Sollicitudo Rei Socialis. Disponible en http://www.vatican.va/holy_father/ john_paul_ii/encyclicals/documents/hf_jp-ii_enc_30121987_sollicitudo-rei-socialis_ sp.html

Jardine, M. (2004). Sight, Sound and Participatory Symbolization. Eric Voegelin's Political Theory as an Attempt to Recapture the Speech-Dimension of Human Experience. En P. A. Petrakis y C. L. Eubanks, Eric Voegelin's Dialogue with the Posmoderns (pp. 57-92). Columbia: University of Missouri Press.

Jonas, H. (2001). The Gnostic Religion. Boston: Beacon Press.

Laclau, E. (2006). On the Names of God. En H. de Vries y L. Sullivan (eds.), Political Theologies. Public Religions in a Post-Secular World (pp. 137-47). Nueva York: Fordham University Press.

Lefort, C. (2006). The Permanence of the Theologico-Political? En H. de Vries y L. Sullivan (eds.), Political Theologies. Public Religions in a Post-Secular World (pp. 148-87). Nueva York: Fordham University Press.

Löwy, M. (1999). Guerra de dioses. Religión y politica en América Latina. México D.F.: Siglo XXI.

Manemann, J. (2002). CarlSchmitt und die Politische Theologie. Politischer Anti-Monotheismus. Münster: Aschendorff.

McAllister, T. V. (1995). Revolt Against Modernity. Leo Strauss, Eric Voegelin \& the Search for a Postliberal Order. Kansas: University Press of Kansas.

Metz, J.-B. (2007). Memoria passionis. Una evocación provocadora en una sociedad pluralista. Santander: Sal Terrae.

Ortiz, G. (2013). América Latina, ¿una modernidad diferente? Córdoba: EDUCC.

Petrakis, P. A. (2004). Voegelin and Ricoeur. Recovering Science and Subjectivity through Representation. En P. A. Petrakis y C. L. Eubanks, Eric Voegelin's Dialogue with the Posmoderns (pp. 23-56). Columbia: University of Missouri Press.

Rosenzweig, F. (1997). La estrella de la redención. Salamanca: Sígueme.

Schmitt, C (1950). Der Nomos der Erde im Völkerrecht des Jus Publicum Europaeum. Köln: Greven.

(2009). Teología politica. Madrid: Trotta.

(2011). Catolicismo romano y forma politica. Madrid: Tecnos.

Scott, P., Cavanaugh, W., eds. (2004). The Blackwell Companion to Political Theology. Malden: Blackwell.

Strauss, L. (1997). Jewish Philosophy and the Crisis of Modernity. Albany: State University of New York Press.

Taubes, J. (2007). La teología politica de Pablo. Madrid: Trotta. 
Topitsch, E. (1988). Erkenntnis und Ilusion: Grundstrukturen unserer Weltauffassung. Tübingen: Mohr.

Voegelin, E. (1989). Autobiographical Reflections. Baton Rouge: Louisiana University Press. (2000a). Modernity Without Restraint. The Collected Works of Eric Voegelin, Vol. 5. Columbia: University of Missouri Press.

(2000b). Order and History III, Plato and Aristotle. The Collected Works of Eric Voegelin, Vol. 16. Columbia: University of Missouri Press. 